\title{
Prophylactic Gastrostomy in Locally Advanced Head and Neck Cancer: Results of A National Survey Among Radiation Oncologists
}

\section{Tatiana Dragan ( $\sim$ tatiana.dragan@bordet.be )}

Jules Bordet Institute: Institut Jules Bordet https://orcid.org/0000-0002-3406-1683

\section{Fréderic Duprez}

UZ Gent: Universitair Ziekenhuis Gent

\section{André Van Gossum}

Jules Bordet Instituut: Institut Jules Bordet

\section{Akos Gulyban}

Jules Bordet Instituut: Institut Jules Bordet

\section{Sylvie Beauvois}

Jules Bordet Instituut: Institut Jules Bordet

\section{Antoine Digonnet}

Jules Bordet Instituut: Institut Jules Bordet

\section{Yassine Lalami}

Jules Bordet Instituut: Institut Jules Bordet

\section{Dirk Van Gestel}

Jules Bordet Instituut: Institut Jules Bordet

\section{Research article}

Keywords: Endoscopic gastrostomy, Head and neck cancer, Radiotherapy, Survey

Posted Date: October 1st, 2020

DOI: https://doi.org/10.21203/rs.3.rs-70709/v1

License: (c) (i) This work is licensed under a Creative Commons Attribution 4.0 International License. Read Full License

Version of Record: A version of this preprint was published at BMC Cancer on June 2 nd, 2021. See the published version at https://doi.org/10.1186/s12885-021-08348-9. 


\section{Abstract}

Background: Nutritional complications in patients with locally advanced head and neck cancer (LA-HNC) treated by concurrent chemoradiotherapy (CCRT) often lead to placement of a prophylactic gastrostomy (PG) tube, while indication lacks harmonization. Our aim was to explore the current PG tube utilization among Belgian radiation oncology centers.

Methods: A survey was distributed to all 24 Belgian Radiation oncology departments, with questions about the number of patient treated per year, whether the PG indication is discussed at the multidisciplinary board, placement technique, time of starting nutrition and removal, its impact on swallowing function and importance of clinical factors. For the latter Relative Importance and Discordance Indexes were calculated to describe the ranking and agreement.

Results: All 24 center submitted the questionnaire. Twenty three treat more than 20 head and neck (HNC) patients per year, while four (1 in 21-50; 3 in 51-100) are not discussing the gastrostomy tube indication at the multidisciplinary board. For the latter, endoscopic placement (68\%) is the dominant technique, followed by the radiologic (16\%) and laparoscopic (16\%) methods. Seventy-five percent start the enteral nutrition when clinically indicated, $17 \%$ immediately and $8 \%$ from the start of radiotherapy. Majority of specialists (19/24) keep the gastrostomy tube until the patient assume an adequate oral feeding. Fifteen centres are considering PG decrease swallowing function. Regarding factors and their importance in the decision for the PG, foreseen irradiated volume reached highest importance, followed by 'anatomical site', 'patients' choice' and 'postoperative versus definitive' and 'local expertise', with decreasing importance respectively. Disagreement indexes showed moderate variation.

Conclusions: The use of a PG tube for LAHNC patients treated by CCRT shows disparity at national level. Prospective studies are needed to ensure proper indication of this supportive measure.

\section{Background}

Chemotherapy combined with Intensity modulated radiation therapy is the standard of care in organ preserving, definitive therapy for locally advanced head and neck cancer (LA-HNC) patients $(1,2)$. Advances such as accelerated radiotherapy and concurrent chemoradiation (CCRT) have improved the tumor related prognosis (3-6). The addition of cisplatin-based chemotherapy improves both locoregional control and overall survival (OS) when compared with radiotherapy alone, but at the price of a substantial increase in severe toxicity (7). Toxicities which occur during CCRT like mucositis, swallowing disorders, xerostomia and taste distortion often impact on oral intake with an increased risk of malnutrition, dehydration, low recovery of symptoms and weight loss. This may affect the treatment compliance with a detrimental impact on disease control (8). Furthermore, a poor nutritional status before and during treatment may be associated with a worse clinical outcome and quality of life (9-11). The gastrostomy feeding tube is the most common approach to improve nutrition in HNC patients undergoing CCRT. In patients without dysphagia before the initiation of CCRT there is no consensus regarding the optimal 
timing for the gastrostomy tube placement (12). Certain centers prefer a prophylactic placement, others a reactive, i.e. when clinically indicated. The risk factors to determine who will benefit from a PG tube are not well defined and the impact on late swallowing function is unclear (13). Late dysphagia has previously been found a very frequent complaint $(\approx 43 \%)$ and one of the most relevant side-effects after HNC treatment, with an impact on quality of life which is even more important than the impact of xerostomia $(7,14)$. In some situations $(13 \%)$ this might even lead to long term gastrostomy feeding tube use (> 2 years after treatment) (7). The systematic intervention of a speech therapist, on the other hand, can prevent late dysphagia in some and lower its intensity in others (15).

We conducted this survey in order to explore the current practice on PG tubes in Belgian radiation oncology departments by collecting general information and expertise in the treatment of HNC patients and to see whether there is a national consensus.

\section{Methods}

The survey contained nine questions. The following issues were assessed: the importance of a multidisciplinary board in taking decisions, the decisive factors for the indication of PG tube placement, the techniques of gastrostomy tube placement available in each centre, the nutritional management after PG tube placement and the specialist's opinion on the PG's impact on late swallowing function after CCRT (Table 1).

All questions were defined and approved in consensus by a multidisciplinary team of specialists involved in the treatment of the HNC patients: specialised clinical nurse, speech pathologist, dietitian, gastroenterologist, radiation oncologist, medical oncologist and head and neck surgeon. The survey was designed by the web application Survey Monkey and was sent via email to the 24 radiation oncologists specialised in the HNC treatment from all 24 primary Belgian radiotherapy departments. An initial email with a brief explanation of the study and an invitation to complete the survey was sent in August, 2019, and a reminder email for those who had not completed the survey was sent in January, 2020.

Respondents had to answer all questions in the survey before they could submit it.

\section{Data analysis and statistics}

Survey data was analysed with descriptive statistics using Microsoft Excel (version 2016, Redmond, Washington, USA). Results are reported in absolute and relative frequencies. To analyse the data under question 4, the responses were summed so that each clinical factor received a score for the number of respondents at each degree of importance ( 1 being very important to 5 being not at all important). We used the Relative Importance Index (RII):

Relative Importance Index $(\mathrm{RII})=\frac{\sum w}{A \cdot N}=\frac{5 \cdot n_{5}+4 \cdot n_{4}+3 \cdot n_{3}+2 \cdot n_{2}+1 \cdot n_{1}}{5 \cdot N}$ 
Where $\boldsymbol{w}$ is the weighting given to each factor (in this case from 1 to 5 ), $\boldsymbol{n}_{\boldsymbol{x}}$ represents the number of respondents for importance $\boldsymbol{X}, \boldsymbol{N}$ is the total number of replies and $\boldsymbol{A}$ corresponds to the highest score (in our case $\boldsymbol{A}=5$ ), resulting the RII between 0 and 1 . These values then were used to determine the rank (from 1 to 5 , for each question).

To assess the disagreement we introduced the Relative Discordance Index (RDI) as follows:

$$
\begin{aligned}
& \text { Relative Discordance Index }=\frac{\sum r}{A \cdot N} \\
& \qquad=\frac{\left|r_{5}-5\right| \cdot n_{5}+\left|r_{4}-4\right| \cdot n_{4}+\left|r_{3}-3\right| \cdot n_{3}+\left|r_{2}-2\right| \cdot n_{2}+\left|r_{1}-1\right| \cdot n_{1}}{5 \cdot N}
\end{aligned}
$$

where $\boldsymbol{r}$ is the weighting discordance for each factor (in this case from 1 to 5 ), $\boldsymbol{r}_{\boldsymbol{x}}$ and $\boldsymbol{n}_{\boldsymbol{x}}$ represents the rank and number of respondents for importance $\boldsymbol{X}, \boldsymbol{N}$ is the total number of replies and $\boldsymbol{A}$ corresponds to the highest score (in our case $\boldsymbol{A}=5$ ), leading to an agreement ranking by assigning from 1 to 5 corresponding to the increase in RDI values (best agreement has lowest RDI).

\section{Results}

All Belgian Radiation Oncology departments filled out the questionnaire. Figure 1 illustrates the number of HNC patients treated in each radiation oncology department per year.

Twenty centres (83\%) stated the indication for gastrostomy tube placement to be discussed at the multidisciplinary board, four centres do not discuss it multidisciplinary. The most commonly used technique is endoscopic placement (68\%), followed by the radiologic (16\%) and laparoscopic (16\%) method. Twenty nine percent stated that more than one option is used in their centre.

Figure 2 shows five factors and their importance in the decision for the PG in case of a LA-HNC patient, without dysphagia nor contraindications for gastrostomy, with normal nutritional status who is about to undergo CCRT.

The results of the Relative Importance Index, Relative Discordance Index and the corresponding ranking of importance and agreement are presented in Table 2.

'Foreseen irradiated volume' was considered the most important, even with the highest disagreement, followed by 'anatomical site' with moderate agreement. 'Patients' choice' and 'postoperative versus definitive settings' showed the best agreement at important and slightly important scores, while 'local expertise' was considered least important with moderate agreement. When considering the start of enteral nutrition via PG, 75\% (18/24) responded 'when clinically indicated', 17\% (4/24) 'immediately following the PG placement' and 8\% (2/24) 'from the start of radiotherapy'. Seventy nine percent of specialists (19/24) would keep the gastrostomy tube until the patient is able to assume an adequate oral feeding, $4 \%(1 / 24)$ awaits the patient to be considered in complete remission while $17 \%(4 / 24)$ expect both criteria to be 
fulfilled. Sixty three percent (15/24) stated that in their opinion the use of the PG could have a negative impact on the swallowing function after CCRT; 33\% (8/24) did not expect impact and 4\% (1/24) did not had an opinion.

\section{Discussion}

The use of a PG tube to prevent malnutrition in HNC patients receiving definitive CCRT has gained a lot of attention in recent literature; however, the appropriate guidelines in clinical practice have not been established yet. This survey reporting on the Belgian HNC radiation oncologists' current clinical practice and their opinion on whether and when to consider a PG tube had a $100 \%$ response rate.

Ninety six percent of centers reported to yearly irradiate more than $20 \mathrm{HNC}$ patients and $71 \%$ even treat more than 50 . Facility volume improves a variety of clinical processes, including access to supportive care such as pain management, swallow/speech therapy and nutrition that increase the probability of treatment completion, minimize the likelihood of treatment interruptions, and mitigate morbidity. There is an emergent body of evidence that patients with HNC who are treated at high-volume centers also have better outcomes (16-19). Within a randomized trial of the Radiation Therapy Oncology Group (RTOG 0129), which compared cisplatin concurrent with standard versus accelerated fractionation radiotherapy Wuthrick et al. found the 5 -year OS rate to be $69.1 \%$ vs $51.0 \%(p=.002)$, respectively, for patients treated at historically low- vs high-accruing centers (20). In 2019, the Belgian Health Care Knowledge Centre (KCE) published an evaluation report on the quality of care in HNC patients in Belgian hospitals according to quality indicators and objectives defined by a panel of experts. According to this KCE report, 9175 head and neck squamous cell carcinoma (SCC) were treated in 99 different centers during the six year study period. It was noted that the median survival of patients treated in high-volume centers (hospitals treating more than 20 patients per year) was 1.1 year longer than their peers treated in low-volume centers (5.1 versus 4.0 years) (21). Regarding radiotherapy volume, 4539 head and neck squamous cell carcinoma (HNSCC) were treated in Belgian radiotherapy (RT) centers between 2009 and 2014. The median RT center volume was 169 patients over the six year period (i.e. 28 patients per year) with a quarter of the centers treating less than 17 patients per year. There was no statistically significant association between RT center volume and overall survival among patients with HNSCC $(p=0.61)$. Assuming that our respondents' answers are in agreement with the clinical practice, $96 \%$ of Belgian radiotherapy centers are in line with this quality indicator of offering personalized care and treatment to more than $20 \mathrm{HNC}$ patients per year. The difference with KCE numbers of treated patients in RT departments can be explained by the KCE selection criteria which included only first treatments for SCC of the oral cavity, oropharynx, hypopharynx and larynx (nasal cavities, thyroid and salivary glands excluded) while 3287 patients $(26 \%)$ with multiple synchronous tumors were left out of the analysis.

We found $83 \%$ of all gastrostomy tube indications to be discussed in a HNC dedicated multidisciplinary board. In the absence of a golden standard, the role of the interdisciplinary team is crucial to assess for each case the appropriateness of a nutritional intervention (22). A multidisciplinary approach provides more accurate treatment recommendations, communication, reinforces cooperation, coordination and 
adherence to clinical guidelines (23)(22). The combination of a HNC multidisciplinary expert team in a high volume referral cancer centre is considered an important indicator of quality of care for HNC and associated with better therapeutic decisions (24).

The most interesting results from our survey include the different factors and their importance in the decision for the PG in case of a HNC patient. Predicting which patient will benefit from PG is challenging. However, we were able to evaluate a number of factors that may correlate with the development of swallowing dysfunction during CRT. The foreseen irradiated mucosal volume, followed by anatomical site has been considered most important by the respondents. It is clear that the irradiated mucosal volume is different in function of anatomical site and lymph node involvement. Many studies have demonstrated a relationship between the dose received by anatomical structures involved in swallowing (e.g. the superior pharyngeal constrictor muscle) and radiation induced acute and late dysphagia. (25-31). Subsequently, several studies are currently focusing on reducing the elective radiation dose and the irradiated volume in order to decrease acute and late swallowing dysfunction (32-35). Langendijk et al. developed a predictive model to identify patients at high risk of radio-induced dysphagia (14). Advanced tumour stage (T3-T4), oropharyngeal and nasopharyngeal tumour site, primary and bilateral neck irradiation, weight loss at baseline, and treatment modality (accelerated RT or CCRT) were identified as independent factors predicting swallowing dysfunction. In Belgium, such studies are focussing on reduction of the elective dose and on volume individualisation of the prophylactic nodal target irradiated zone using the identification of the sentinel node $(33,35)$.

Another factor we evaluated is the patient's choice. Despite the growing interest in supporting the patient's participation in clinical decisions, there is no evidence to guide clinicians regarding the level of patients' involvement in the decision-making process. Patient's preference for involvement may vary between those preferring to take part on their own treatment, to those who prefer to leave treatment decisions to their medical team, largely as patients report lacking the specialized knowledge needed to make treatment decisions (36).

Swallowing dysfunction also has a significant impact on health-related quality of life, even more than xerostomia, as reported by patients (14). Prophylactic endoscopic gastrostomy (PEG) tube may also negatively affect the psychological status of the patients as it may interfere with family life, intimate relationships and social activities (37). However, a recent systematic review of the effect on enteral tube feeding on health related quality of life suggests PG placement to be effective in improving quality of life for patients with HNC cancers treated with CCRT (38).

The respondents accorded moderate importance in the decision making regarding PG tube to the sort of multimodality treatment, more precisely the postoperative versus definitive setting. Surgery before radiotherapy and extent of reconstruction appear to be important factors to develop swallowing problems during postoperative treatment (39-41). Finally, local expertise and available techniques are important in the planning of the PEG tube. Different techniques of PEG placement are available across the Belgian radiotherapy centres, with endoscopic placement being the most commonly used (68\%). There are, 
however, no randomised trials comparing these different techniques, hence current evidence is only based on retrospective and non-randomized controlled studies (42). It is recommended to base the choice of the technique on indications and contraindications, local experience and the available techniques (43). Complications related to the PEG tube placement by different techniques are quite rare and range from minor infections and bleeding to peritonitis (44). One of the most serious complications is abdominal wall metastasis following PEG placement. This risk is correlated with advanced tumour stage, tumour biology and the technique (45). As such, the "Pull" technique instead of the "Push" technique was identified as a risk factor in a large retrospective study with $777 \mathrm{HNC}$ patients where the incidence of abdominal wall metastasis was $0.64 \%(46)$.

Regarding optimal starting of the enteral nutrition, the majority of respondents opted to start nutritional support when clinically indicated, more specifically in case of deterioration of swallowing or nutritional status including weight loss. As the CCRT side effects usually start around the second or third week of treatment, patients could continue oral food intake these first couple of weeks of radiotherapy. The benefit of the maintenance of oral intake was demonstrated by Hutcheson et al. who retrospectively analysed swallowing outcome in 497 HNC patients treated with CCRT. Maintenance of oral intake throughout treatment was associated with better long term swallowing function and less long term gastrostomy dependency (15). Brown et al conducted a randomized controlled study comparing early versus postponed feeding nutrition (i.e. when clinically indicated) in HNC patients with PG tube placement. They concluded that early use of the PG tube did not result in an increase in long term dependency. However, swallowing outcome measurements were not included in this study (47). As there are no general guidelines on when to remove the gastrostomy the majority of survey respondents opted to wait until the patient is able to assume an adequate oral feeding. Alternatively, it is defendable to wait for the first follow up exams to ensure that no further salvage therapy is required. Salvage treatment such as neck dissection could increase the risk of PEG tube dependency in HNC patients (48).

One of the most interesting results from the data presented is the disparity with regard to the influence of PG tube on swallowing outcome. This is consistent with published evidence on the possible negative effect of PG tube placement on long-term swallowing function (49-51). Shaw et al. conducted a systematic review on this subject and concluded to a lack of consensus in literature regarding the impact on late swallowing function of the use of a PG (13). We found the main debate to be about the importance of maintaining adequate nutrition during treatment versus maintaining swallowing function.

There are some limitations of this study. The first and most important is the subjective matter given the survey is opinion based. The questions were designed with the multidisciplinary team for clarity and reliability however they have not been tested before being sent to the participants. Additionally, only a single national speciality was surveyed (radiation oncology), while the opinions of head and neck surgeons, medical oncologists and other physicians who care for HNC patients being clearly important, they were outside of the scope of this survey.

\section{Conclusions}


This survey confirms the decision making for the placement and use of a PG tube in the context of LAHNC patients undergoing CCRT to be a complex process with a widely variable clinical practice. There is an imperative necessity for standardisation of recommendations and clinical guidelines. Further solid research is essential to support a better, evidence based clinical practice.

\section{List Of Abbreviations}

CCRT concurrent chemoradiotherapy

HNC head and neck cancer

HNSCC head and neck squamous cell carcinoma

KCE Belgian Health Care Knowledge Centre

LA-HNC locally advanced head and neck cancer

OS overall survival

PEG prophylactic endoscopic gastrostomy

PG prophylactic gastrostomy

RDI Relative Discordance Index

RII Relative Importance Index

$\mathrm{RT}$ radiotherapy

RTOG Radiation Therapy Oncology Group

\section{Declarations}

\section{Ethics approval and consent to participate}

Not applicable as no patient's data were collected

Consent for publication

Not applicable

\section{Availability of data and materials}

All data generated or analysed during this survey are included in this published article. 
The authors declare that the research was conducted in the absence of any commercial or financial relationships that could be construed as a potential conflict of interest.

\section{Funding}

No funding was received for this project.

\section{Author's contributions}

DT and DVG designed and implemented the research. DT wrote the first draft of the manuscript and DVG and FD revised it critically for important intellectual content. AVG, $A G, S B, A D$ and $Y L$ discussed the results and commented on the manuscript. All authors approved the submitted version.

\section{Acknowledgements}

The authors would like to acknowledge and thank the radiation oncologists from the Belgian Radiation Oncology departments for their participation, time and contribution.

\section{References}

1. Gregoire V, Lefebvre J-L, Licitra L, Felip E. Squamous cell carcinoma of the head and neck: EHNSESMO-ESTRO Clinical Practice Guidelines for diagnosis, treatment and follow-up. Ann Oncol [Internet]. 2010 May 1 [cited 2018 Feb 19];21(Supplement 5):v184-6. Available from: https://academic.oup.com/annonc/article-lookup/doi/10.1093/annonc/mdq185

2. Foote RL, Gillison ML, Haddad RI, Hicks WL, Hitchcock YJ, Jimeno A, et al. Continue NCCN Guidelines Panel Disclosures NCCN Guidelines Version 3.2019 Head and Neck Cancers NCCN Evidence Blocks TM [Internet]. 2019 [cited 2019 Nov 21]. Available from: www.nccn.org/patients.

3. Pignon J-P, le Maître A, Maillard E, Bourhis J, MACH-NC Collaborative Group. Meta-analysis of chemotherapy in head and neck cancer (MACH-NC): an update on 93 randomised trials and 17,346 patients. Radiother Oncol [Internet]. 2009 Jul [cited 2018 Apr 12];92(1):4-14. Available from: http://linkinghub.elsevier.com/retrieve/pii/S0167814009001881

4. Blanchard P, Landais C, Petit C, Zhang Q, Grégoire V, Tobias J, et al. Meta-analysis of chemotherapy in head and neck cancer (MACH-NC): An update on 100 randomized trials and 19,248 patients, on behalf of MACH-NC group. Ann Oncol [Internet]. 2016 Oct [cited 2019 Nov 18];27(suppl_6). Available from:

http://academic.oup.com/annonc/article/doi/10.1093/annonc/mdw376.02/2799687/Metaanalysisof-chemotherapy-in-head-and-neck

5. Adelstein DJ, Li Y, Adams GL, Wagner H, Kish JA, Ensley JF, et al. An intergroup phase III comparison of standard radiation therapy and two schedules of concurrent chemoradiotherapy in patients with unresectable squamous cell head and neck cancer. J Clin Oncol [Internet]. 2003 Jan 1 [cited 2018 Sep 6];21(1):92-8. Available from: http://ascopubs.org/doi/10.1200/JC0.2003.01.008 
6. Szturz P, Wouters K, Kiyota N, Tahara M, Prabhash K, Noronha V, et al. Altered fractionation radiotherapy combined with concurrent low-dose or high-dose cisplatin in head and neck cancer: $\mathrm{A}$ systematic review of literature and meta-analysis. Vol. 76, Oral Oncology. Elsevier Ltd; 2018. p. 5260 .

7. Machtay M, Moughan J, Trotti A, Garden AS, Weber RS, Cooper JS, et al. Factors associated with severe late toxicity after concurrent chemoradiation for locally advanced head and neck cancer: An RTOG analysis. J Clin Oncol [Internet]. 2008 Jul 20 [cited 2018 Feb 19];26(21):3582-9. Available from: http://www.ncbi.nlm.nih.gov/pubmed/18559875

8. Thomas K, Martin T, Gao A, Ahn C, Wilhelm H, Schwartz DL. Interruptions of Head and Neck Radiotherapy Across Insured and Indigent Patient Populations. J Oncol Pract. 2017 Apr 7;13(4):e319-28.

9. Zeng Q, Shen LJ, Guo X, Guo XM, Qian CN, Wu PH. Critical weight loss predicts poor prognosis in nasopharyngeal carcinoma. BMC Cancer [Internet]. 2016 Feb 29 [cited 2020 Mar 19];16(1):169. Available from: http://www.biomedcentral.com/1471-2407/16/169

10. Langius JAE, Bakker S, Rietveld DHF, Kruizenga HM, Langendijk JA, Weijs PJM, et al. Critical weight loss is a major prognostic indicator for disease-specific survival in patients with head and neck cancer receiving radiotherapy. Br J Cancer. 2013 Sep;109(5):1093-9.

11. Baptistella A, Hilleshein K, Beal C, Brambatti J, Caron R, Baptistella S, et al. Weight loss as a prognostic factor for recurrence and survival in oropharyngeal squamous cell carcinoma patients. Mol Clin Oncol. 2018 Oct 5;9(6):666.

12. Bradley PT, Brown T, Paleri V. Gastrostomy in head and neck cancer: Current literature, controversies and research [Internet]. Vol. 23, Current Opinion in Otolaryngology and Head and Neck Surgery. Lippincott Williams and Wilkins; 2015 [cited 2020 Apr 2]. p. 162-70. Available from: http://www.ncbi.nlm.nih.gov/pubmed/25692626

13. Shaw SM, Flowers H, O'Sullivan B, Hope A, Liu LWC, Martino R. The Effect of Prophylactic Percutaneous Endoscopic Gastrostomy (PEG) Tube Placement on Swallowing and Swallow-Related Outcomes in Patients Undergoing Radiotherapy for Head and Neck Cancer: A Systematic Review. Dysphagia [Internet]. 2015 Apr 4 [cited 2018 Jul 6];30(2):152-75. Available from: http://link.springer.com/10.1007/s00455-014-9592-z

14. Langendijk JA, Doornaert P, Verdonck-de Leeuw IM, Leemans CR, Aaronson NK, Slotman BJ. Impact of late treatment-related toxicity on quality of life among patients with head and neck cancer treated with radiotherapy. J Clin Oncol. 2008;26(22):3770-6.

15. Hutcheson KA, Bhayani MK, Beadle BM, Gold KA, Shinn EH, Lai SY, et al. Eat and exercise during radiotherapy or chemoradiotherapy for pharyngeal cancers: Use it or lose it. JAMA Otolaryngol Head Neck Surg. 2013 Nov;139(11):1127-34.

16. Verma V, Allen PK, Simone CB, Gay HA, Lin SH. Association of treatment at high-volume facilities with survival in patients receiving chemoradiotherapy for nasopharyngeal cancer. JAMA Otolaryngol - Head Neck Surg. 2018;144(1):86-9. 
17. Naghavi AO, Echevarria MI, Strom TJ, Abuodeh YA, Venkat PS, Ahmed KA, et al. Patient choice for high-volume center radiation impacts head and neck cancer outcome. Cancer Med. 2018 Oct 1;7(10):4964-79.

18. David JM, Ho AS, Luu M, Yoshida EJ, Kim S, Mita AC, et al. Treatment at high-volume facilities and academic centers is independently associated with improved survival in patients with locally advanced head and neck cancer. Cancer [Internet]. 2017 Oct 15 [cited 2019 Sep 1];123(20):3933-42. Available from: http://doi.wiley.com/10.1002/cncr.30843

19. Peters LJ, O'Sullivan B, Giralt J, Fitzgerald TJ, Trotti A, Bernier J, et al. Critical impact of radiotherapy protocol compliance and quality in the treatment of advanced head and neck cancer: results from TROG 02.02. J Clin Oncol [Internet]. 2010 Jun 20 [cited 2019 Jun 17];28(18):2996-3001. Available from: http://ascopubs.org/doi/10.1200/JC0.2009.27.4498

20. Wuthrick EJ, Zhang Q, Machtay M, Rosenthal DI, Nguyen-Tan PF, Fortin A, et al. Institutional clinical trial accrual volume and survival of patients with head and neck cancer. J Clin Oncol [Internet]. 2015 Jan 10 [cited 2019 Jun 17];33(2):156-64. Available from: http://ascopubs.org/doi/10.1200/JC0.2014.56.5218

21. Roos L, Cindy DG, Sabine S, Geert S, Leen V, Viki S, et al. Quality indicators for the management of head and neck squamous cell carcinoma [Internet]. KCE Reports. Brussels: Belgian Health Care Knowledge Centre (KCE); 2019. Available from: https://kce.fgov.be/report/305

22. Taberna M, Gil Moncayo F, Jané-Salas E, Antonio M, Arribas L, Vilajosana E, et al. The Multidisciplinary Team (MDT) Approach and Quality of Care. Vol. 10, Frontiers in Oncology. Frontiers Media S.A.; 2020.

23. Rosell L, Alexandersson N, Hagberg O, Nilbert M. Benefits, barriers and opinions on multidisciplinary team meetings: A survey in Swedish cancer care. BMC Health Serv Res. 2018 Apr 5;18(1):1-10.

24. Trama A, Botta L, Foschi R, Visser O, Borras JM, Žagar T, et al. Quality of care indicators for head and neck cancers: The experience of the European project RARECAREnet. Front Oncol. 2019;9(AUG).

25. Christianen MEMC, Schilstra C, Beetz I, Muijs CT, Chouvalova O, Burlage FR, et al. Predictive modelling for swallowing dysfunction after primary (chemo)radiation: Results of a prospective observational study. Radiother Oncol. 2012 Oct 1;105(1):107-14.

26. Kannan RA, Arul Ponni TR. Dose to swallowing structures and dysphagia in head and neck Intensity Modulated Radiation Therapy - A long term prospective analysis. Reports Pract Oncol Radiother. 2019 Nov 1;24(6):654-9.

27. Otter S, Schick U, Gulliford S, Lal P, Franceschini D, Newbold K, et al. Evaluation of the Risk of Grade 3 Oral and Pharyngeal Dysphagia Using Atlas-Based Method and Multivariate Analyses of Individual Patient Dose Distributions Presented at the 54th Annual Meeting of the American Society for Radiation Oncology, Boston, MA, Oc. In: International Journal of Radiation Oncology Biology Physics. Elsevier Inc.; 2015. p. 507-15.

28. Ozkaya Akagunduz O, Eyigor S, Kirakli E, Tavlayan E, Erdogan Cetin Z, Kara G, et al. RadiationAssociated Chronic Dysphagia Assessment by Flexible Endoscopic Evaluation of Swallowing (FEES) 
in Head and Neck Cancer Patients: Swallowing-Related Structures and Radiation Dose-Volume Effect. Ann Otol Rhinol Laryngol [Internet]. 2019 Feb 20 [cited 2020 May 3];128(2):73-84. Available from: http://journals.sagepub.com/doi/10.1177/0003489418804260

29. Chen AM, Hsu S, Meshman J, Chin R, Beron P, Abemayor E, et al. Effect of daily fraction size on laryngoesophageal dysfunction after chemoradiation for squamous cell carcinomas of the larynx and hypopharynx. Head Neck [Internet]. 2017 Jul 1 [cited 2020 May 3];39(7):1322-6. Available from: http://doi.wiley.com/10.1002/hed.24757

30. Eisbruch A, Lyden T, Bradford CR, Dawson LA, Haxer MJ, Miller AE, et al. Objective assessment of swallowing dysfunction and aspiration after radiation concurrent with chemotherapy for head-andneck cancer. Int J Radiat Oncol Biol Phys [Internet]. 2002 May 1 [cited 2019 Jun 29];53(1):23-8. Available from: http://www.ncbi.nlm.nih.gov/pubmed/12007937

31. Levendag PC, Teguh DN, Voet P, van der Est H, Noever I, de Kruijf WJM, et al. Dysphagia disorders in patients with cancer of the oropharynx are significantly affected by the radiation therapy dose to the superior and middle constrictor muscle: A dose-effect relationship. Radiother Oncol [Internet]. 2007 Oct [cited 2019 Jun 17];85(1):64-73. Available from: https://linkinghub.elsevier.com/retrieve/pii/S0167814007003453

32. Randomized Trial of Intensity-Modulated Proton Beam Therapy (IMPT) Versus Intensity-Modulated Photon Therapy (IMRT) for the Treatment of Oropharyngeal Cancer of the Head and Neck - Full Text View - ClinicalTrials.gov [Internet]. [cited 2020 May 3]. Available from: https://clinicaltrials.gov/ct2/show/NCT01893307? term=IMPT\&cond=Head+and+Neck+Neoplasms\&draw=2\&rank=1

33. Deschuymer S, Nevens D, Duprez F, Daisne JF, Dok R, Laenen A, et al. Randomized clinical trial on reduction of radiotherapy dose to the elective neck in head and neck squamous cell carcinoma; update of the long-term tumor outcome. Radiother Oncol. 2020 Feb 1;143:24-9.

34. Meijer TWH, Scandurra D, Langendijk JA. Reduced radiation-induced toxicity by using proton therapy for the treatment of oropharyngeal cancer. Br J Radiol [Internet]. 2020 Mar 1 [cited 2020 May 3];93(1107):20190955. Available from: https://www.birpublications.org/doi/10.1259/bjr.20190955

35. E. Longton MD, Lawson G, Bihin B, Mathieu I, Hanin FX, Deheneffe S, et al. Individualized prophylactic neck irradiation in $\mathrm{cNO}$ head and neck cancer patients based on sentinel lymph node(s) identification: definitive results of a prospective phase I-II study. Int J Radiat Oncol. 2020 Apr 12;

36. Jabbour J, Dhillon HM, Shepherd HL, Sundaresan P, Milross C, Clark JR. The relationship between role preferences in decision-making and level of psychological distress in patients with head and neck cancer. Patient Educ Couns. 2018 Oct 1;101(10):1736-40.

37. Rogers SN, Thomson R, O'Toole P, Lowe D. Patients experience with long-term percutaneous endoscopic gastrostomy feeding following primary surgery for oral and oropharyngeal cancer. Oral Oncol. 2007 May 1;43(5):499-507.

38. Ojo O, Keaveney E, Wang XH, Feng P. The effect of enteral tube feeding on patients' health-related quality of life: A systematic review. Vol. 11, Nutrients. MDPI AG; 2019. 
39. Yang W, McNutt TR, Dudley SA, Kumar R, Starmer HM, Gourin CG, et al. Predictive Factors for Prophylactic Percutaneous Endoscopic Gastrostomy (PEG) Tube Placement and Use in Head and Neck Patients Following Intensity-Modulated Radiation Therapy (IMRT) Treatment: Concordance, Discrepancies, and the Role of Gabapentin. Dysphagia. 2016 Apr 1;31(2):206-13.

40. Hausmann J, Kubesch A, Müller von der Grün J, Goettlich CM, Filmann N, Oliver Tal A, et al. Prophylactic percutaneous endoscopic gastrostomy in patients with head and neck cancer: Influence on nutritional status, utilisation rate and complications. Int J Clin Pract [Internet]. 2019 Nov 13 [cited 2020 May 3];73(11). Available from: https://onlinelibrary.wiley.com/doi/abs/10.1111/ijcp.13405

41. Van Der Linden NC, Kok A, Leermakers-Vermeer MJ, De Roos NM, De Bree R, Van Cruijsen H, et al. Indicators for Enteral Nutrition Use and Prophylactic Percutaneous Endoscopic Gastrostomy Placement in Patients with Head and Neck Cancer Undergoing Chemoradiotherapy. Nutr Clin Pract. 2017 Apr 1;32(2):225-32.

42. Yuan Y, Zhao Y, Xie T, Hu Y. Percutaneous endoscopic gastrostomy versus percutaneous radiological gastrostomy for swallowing disturbances. Vol. 2016, Cochrane Database of Systematic Reviews. John Wiley and Sons Ltd; 2016.

43. Sieron HL, Eberle F, Gress TM, Mahnken AH, Wiegand S. Safety of prophylactic gastrostomy tube placement and gastrostomy tube usage in patients treated by radio(chemo)therapy for head and neck cancer. Anticancer Res. 2020 Feb 1;40(2):1167-73.

44. Rahnemai-Azar AA, Rahnemaiazar AA, Naghshizadian R, Kurtz A, Farkas DT, Nagh-Shizadian R. Percutaneous endoscopic gastrostomy: Indications, technique, complications and management. World J Gastroenterol [Internet]. 2014 [cited 2020 Apr 2];20(24):7739-51. Available from: http://www.wjgnet.com/esps/HelpDesk:http://www.wjgnet.com/esps/helpdesk.aspx

45. Vincenzi F, De Caro G, Gaiani F, Fornaroli F, Minelli R, Leandro G, et al. Risk of tumor implantation in percutaneous endoscopic gastrostomy in the upper aerodigestive tumors. Vol. 89, Acta Biomedica. Mattioli 1885; 2018. p. 117-21.

46. Fung E, Strosberg DS, Jones EL, Dettorre R, Suzo A, Meara MP, et al. Incidence of abdominal wall metastases following percutaneous endoscopic gastrostomy placement in patients with head and neck cancer. Surg Endosc. 2017 Sep 1;31(9):3623-7.

47. Brown T, Banks M, Hughes BGM, Lin C, Kenny LM, Bauer JD. Impact of early prophylactic feeding on long term tube dependency outcomes in patients with head and neck cancer. Oral Oncol. 2017 Sep 1;72:17-25.

48. Lango MN, Egleston B, Ende K, Feigenberg S, D’Ambrosio DJ, Cohen RB, et al. Impact of neck dissection on long-term feeding tube dependence in patients with head and neck cancer treated with primary radiation or chemoradiation. Head Neck [Internet]. 2009 Mar 1 [cited 2020 May 6];32(3):NANA. Available from: http://doi.wiley.com/10.1002/hed.21188

49. Sethugavalar B, Teo MT, Buchan C, Ermiş E, Williams GF, Sen M, et al. Impact of prophylactic gastrostomy or reactive NG tube upon patient-reported long term swallow function following 
chemoradiotherapy for oropharyngeal carcinoma: A matched pair analysis. Oral Oncol. 2016 Aug 1;59:80-5.

50. Ward MC, Bhateja P, Nwizu T, Kmiecik J, Reddy CA, Scharpf J, et al. Impact of feeding tube choice on severe late dysphagia after definitive chemoradiotherapy for human papillomavirus-negative head and neck cancer. Head Neck [Internet]. 2016 Apr 1 [cited 2020 May 6];38(S1):E1054-60. Available from: http://doi.wiley.com/10.1002/hed.24157

51. Langmore S, Krisciunas GP, Miloro KV, Evans SR, Cheng DM. Does PEG use cause dysphagia in head and neck cancer patients? Dysphagia. 2012 Jun 18;27(2):251-9.

\section{Tables}


Table 1

Questions of the survey

\section{Speciality}

\section{Instutution}

3. Is the indication for Prophylactic Gastrostomy discussed at the Yes/No multidisciplinary board?

4. How many patients do you irradiate per year in your center

5. In case of a Locally Advanced Head and Neck Cancer (LAHNC) patient, without dysphagia nor contraindications for gastrostomy, with normal nutritional status who will undergo chemo-radiation, to which degree the following factors would influence your decision: a) the foreseen irradiated volume of oral/oropharyngeal mucosa, constrictor muscles and oesophagus?; b) the anatomical site of the tumour?; c) the postoperative versus curative setting?; d)the patient's choice?; e)the expertise of your centre in gastrostomy placement?

6. In your centre which technique is used to place gastrostomies (you can select more than one if necessary)

7. When do you start enteral nutrition via prophylactic gastrostomy?

8. When do you remove the prophylactic gastrostomy?
$0 / 0-20 / 21-50 / 51-100 />100$

Not at all important/Slightly

Important/Important/Fairly Important/Very Important
Endoscopic/Radiologic/Laparoscopic/Gastrostomies are not used/Other

Immediately following the prophylactic gastrostomy placement/from the start of radiotherapy/Later, when clinically indicated/Other (free text)

At the end of chemo-radiation/When the patient is able to assume an adequate oral feeding/In case of complete locoregional remission at the first evaluation post chemo-radiation/Other, please specify (free text)
9. In your opinion, could the use of a prophylactic gastrostomy have a negative impact on swallowing function after chemoradiation?
Yes/No/No opinion 
Table 2

Ranking of importance and agreement using RII and RDI (based on question nr.5)

\begin{tabular}{|llllll|}
\hline & $\begin{array}{l}\text { anatomical } \\
\text { site }\end{array}$ & $\begin{array}{l}\text { foreseen } \\
\text { irradiated volume }\end{array}$ & $\begin{array}{l}\text { postoperative vs. } \\
\text { definitive }\end{array}$ & $\begin{array}{l}\text { patient's } \\
\text { choice }\end{array}$ & $\begin{array}{l}\text { local } \\
\text { expertise }\end{array}$ \\
\hline $\begin{array}{l}\text { Relative } \\
\text { Importance Index }\end{array}$ & 0.58 & 0.49 & 0.73 & 0.64 & 0.76 \\
\hline $\begin{array}{l}\text { Importance Rank } \\
\begin{array}{l}(1=\text { most, } 5= \\
\text { least })\end{array}\end{array}$ & 2 & 1 & 4 & 3 & 5 \\
\hline $\begin{array}{l}\text { Relative } \\
\text { Discordance }\end{array}$ & 0.24 & 0.29 & & & \\
Index & & & 0.18 & 0.18 & 0.24 \\
$\begin{array}{l}\text { Agreement Rank } \\
\text { (1 = best, } 5=\end{array}$ & 3 & 5 & 1 & 1 & 3 \\
least) & & & & & \\
\hline
\end{tabular}

\section{Figures}

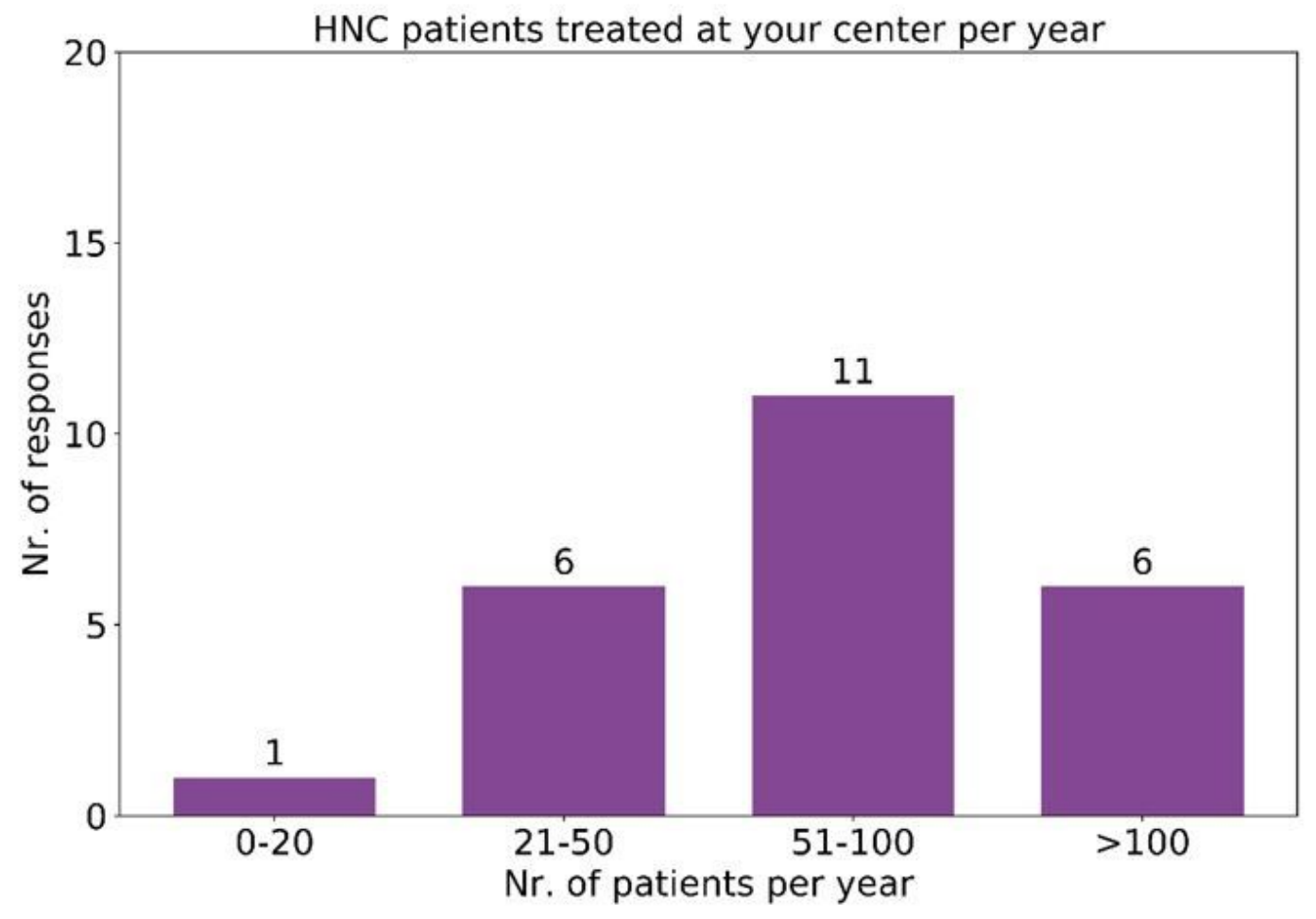

Figure 1

Number of HNC patients treated in each radiation oncology department per year 


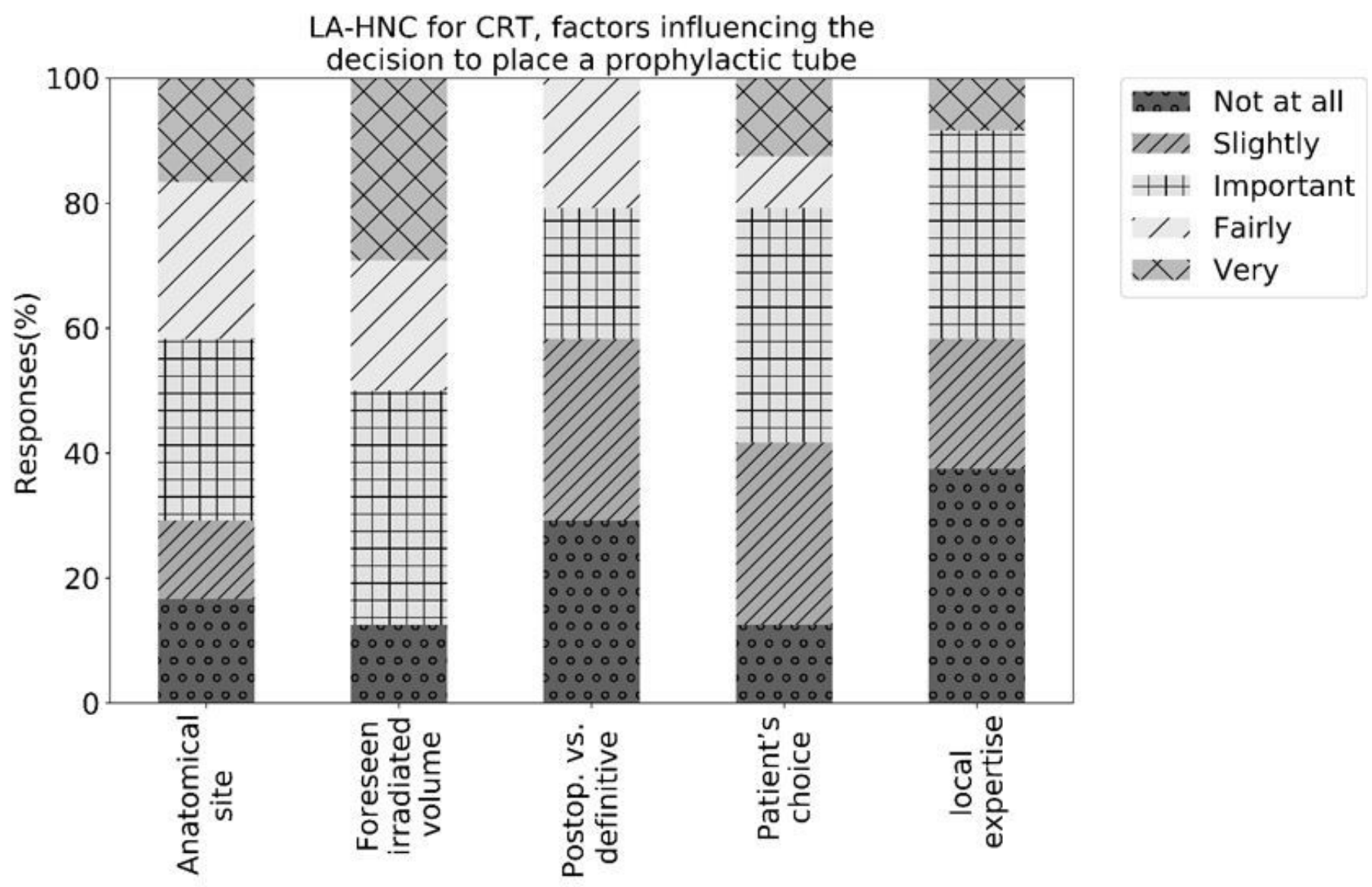

Figure 2

Question 5: Five factors and their importance in the decision for the prophylactic gastrostomy 